\title{
Design and implementation of ozone desulfurization and denitration control system based on PLC and kingview
}

\author{
Mei Lin ${ }^{1, a}$, Chao Sun ${ }^{2}$ and Kai Zhang ${ }^{2}$ \\ ${ }^{1}$ Binzhou Polytechnic, Electrical Engineering College, binzhouShangDong,256600, China \\ ${ }^{2}$ Binyang combustion co. LTD., Quality department, binzhou ShangDong,2566, China
}

\begin{abstract}
In view of the BinYang existing characteristics of the equipment, the programmable controller PLC combined with ozone desulfurization denitration, design the real-time monitoring, the operation is simple, operation is stable, easy to transplant the FGD control system. The upper computer uses the configuration kingview6.5 software to conduct real-time monitoring system operation, storage system data, and display report, curve, alarm and other information. In this paper, the hardware design, control system configuration, interface design and system optimization of flue gas desulfurization control system are introduced

in

detail.
\end{abstract}

\section{Introduction}

According to the standard requirements for the discharge of air pollutants in the boiler of Shandong province (DB37/2374-2013), the emission concentration of carbon dioxide will be reduced to $20 \mathrm{mg} / \mathrm{m}^{3}$ by 2020 , the emission concentration of $\mathrm{SO}_{2}$ will be reduced to 100 $\mathrm{mg} / \mathrm{m}^{3}$, and the Nox emission concentration will be reduced to $200 \mathrm{mg} / \mathrm{m}^{3}$. The boilers of Shandong BingHua BinYang combustion co. LTD. has been constructed with the electrostatic dust removal and magnesium desuric removal device.

Through the actual situation of the three years of operation, when the amount of steam is above $35 \mathrm{t} / \mathrm{h}$ and above $50 \mathrm{t} / \mathrm{h}$ above, the pollutants in the flue gas are exceeded, and the sulfur dioxide is above $400 \mathrm{mg} / \mathrm{m}^{3}$. At present, enterprises adopt low-load operation mode to reduce pollutant emission, but the shortage of heat supply seriously affects the normal production of enterprises. In order to further reduce the emission of pollutants and meet the requirements of new emission standards, at the same time, combined with the development status of the factory, the company decided to upgrade the flue gas treatment system and improve the denitrification facilities.

This project is the boiler exhaust gas treatment project, the construction of the project will effectively reduce the emissions of $\mathrm{NO}_{\mathrm{x}}, \mathrm{SO}_{2}$, smoke and other atmospheric pollutants, in line with national and shandong province of the 12th five-year plan of environmental protection requirements.

\section{Design Process Of Ozone Desulfurization And Desulfurization}

In the study on the basis of the existing boiler supporting facilities, the flue gas desulfurization denitration technology renovation project found that separate construction covers an area of large, complex systems, the removal rate of $\mathrm{SO}_{2}$ and $\mathrm{NOx}$ were lower than the desulfurization of flue gas denitration all-in-one desulfurization denitration removal rate and operation cost is high. At the same time, combined with the new technology of denitrification technology, the project team decided to adopt the ozone desulfurization and sales process, and realized the real-time monitoring, circulation control and information feedback of the smoke link through the intelligent control and control system. Using strong oxidizing of ozone, for combining with materials such as $\mathrm{SO}_{2}$, NOx, a product of the combination can be better integrated into the water, thus using calcium absorb harmful material place, ozone as raw materials, due to its itself is no pollution material, and after the reaction of material and no pollution to the environment, will not cause secondary pollution, is a kind of environmental protection and energy saving.

After upgrading, the flue gas containing $\mathrm{SO}_{2}$ and nitrogen oxides, first it through the electrostatic dust removal device, which collection coefficient as high as 99.5\% into the dust. At the same time, ozone oxidation device to generate ozone after mixing device is mixed with pressurized air through ozone spray gun spray into the reactor with flue gas after fully mixing, ozone oxidation with $\mathrm{NOx}$ gas chemical reaction, generate $\mathrm{NO}_{2}$ high nitrogen oxides, etc. After entering the $\mathrm{MgO}$ style granite desulfuration efficiency (90\%) desulfurization desulfurization tower, lye, in entering the denitration tower and the flue gas to dissolve in water of $\mathrm{NO}_{2}$ and lye fully absorb and into the pool, so as to achieve the purpose of removing NOx. The flue gas is discharged

*Corresponding author: a linq_0324@163.com 
into the public flue through the internal swirl dehydration device.

\section{Control system design}

On the basis of advanced technology and high precision test instrument, ozone desulfurization and desulfurization and desulfurization control system is designed with simple operation, convenient control and minimal intermediate link. Through these can realize the control of flue gas desulfurization and desulfurization.

\section{1 hardware design}

According to the requirements of ozone desulfurization and desulfurization, the system is mainly divided into the following modules, including: control module, ozone generating module, stone tower desulfurization system module, sodium alkali preparation module, the automatic control system for the desulfurization denitration loop control system control module, the $\mathrm{PH}$ value of automatic dosing control system module, backwashing pump control module module, $\mathrm{PH}$ automatic audible and automatic alarm module and human-computer interaction module.

\subsection{1 control module}

The system adopts PLC as the core controller of the system, which is reliable, adaptive and anti-interference. Using Siemens PLC200 CUP226 AC/DC/RLY as control unit, while expanding multiple analog input and output module, switch input and output module. Through the above design, the process signal in the whole process is monitored and collected in real time, and the output feedback is given to each module to realize automatic adjustment function. The process signal in the whole process is monitored and collected in real time and the output feedback is given to each module to realize automatic adjustment function.

\subsubsection{Ozone generating module}

The ozone generating unit is mixed with the pressurized air by the mixing device, and then it is sprayed into the ozone reactor and then mixed with the flue gas. By flue gas sensors to detect the flue gas flow, the use of PLC control module ozone injection time and injection speed gun group, improve the effect of mixed with flue gas, and achieve the goal of energy saving.

\subsubsection{Grinding tower desulphurization module}

Sensors on stone tower outlet flue gas temperature and pressure real-time monitoring, and use the analog module, digital module transfer the information to the PLC control module, when the monitoring data beyond the scope of value or an exception for remote control or manual intervention operation.

\subsubsection{Desulfurization and sale system circulation control module}

When the flue gas enters the desulfurization and denitrification tower, the tower is sprayed with lye so that the $\mathrm{NO}_{2}$ and lye that dissolve in water fully absorb and drain into the pool, thus achieving the purpose of removing NOx. Rotary atomizing nozzle atomization, the tower lye is atomized into droplets size $30 \sim 60$ mum, these small droplets come into contact with acidic gases $\left(\mathrm{SO}_{2}, \mathrm{NO}_{\mathrm{X}}\right)$, in a series of chemical reactions after removing of flue gas in the vast majority of acid gases $\left(\mathrm{SO}_{2}, \mathrm{NO}_{\mathrm{X}}\right)$. The internal information of the tower sensor is collected in real time, including water level information in the tower, temperature inside the tower, ph of liquid in the tower and pressure inside the tower. The module is the main module of denitration of flue gas and desulfurization.

\subsection{5 sodium alkali preparation module}

This module is composed of 1 set of alkali liquid preparation tank (including agitator), $1 \mathrm{PH}$ controller, 1 bucket feeder, 1 storage hopper, 2 lye booster pump (1 with one backup) and solenoid valve. The solenoid valve controls the water supply in the tank; The PH controller controls the sodium concentration in the tank. When the $\mathrm{PH}$ value of the alkaline liquor is lower than 10 , the bucket feeder will be manually operated with sodium hydroxide and the solenoid valve will automatically open the refill. When the $\mathrm{PH}$ value of the tower is less than 8 , the $\mathrm{PH}$ controller sends the signal to the lye pump, and the lye pump is used to transport lye in the denitrification system. When the liquid level of the flue gas oxidation mixing device is lower than the limit, the solenoid valve is automatically opened to replenish the circulating water in the tower.

\subsubsection{Automatic alarm system module}

When each module values beyond the normal scope, PLC will send alarm signal, warning staff take positive measures, such as PLC communication error, import and export pressure value is too large, the high temperature real-time alarm information.

\section{The software design}

The control system of ozone desulfurization and desulfurization system is designed and designed conforming to the control requirements.

\subsection{PLC control flow chart design}

The purpose of PLC control is to realize the control processing of flue gas desulfurization and desulfurization, mainly including system operation mode selection: manual mode or automatic operation mode, The flue gas is tracked in real time in the condition of flue gas, special case alarm processing and effective communication between information and so on. For example, when the 
PLC is opened, the system is initialized. After the system initialization is completed, it is in a waiting state, waiting for the manual operation to switch or the automatic operation of PLC. The flow diagram is shown in Figure 1:

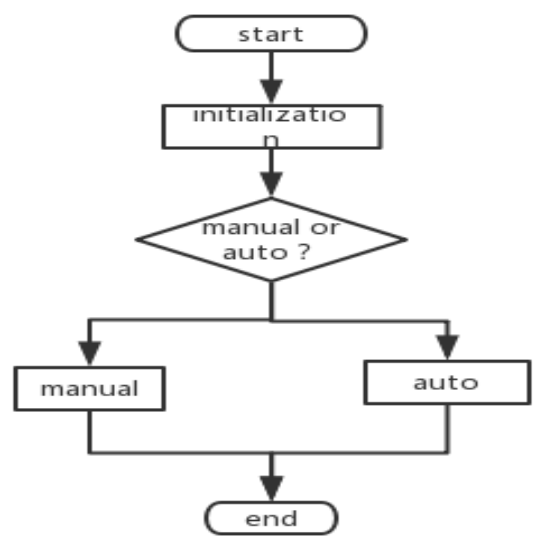

Figure 1. PLC distribution cabinet. flow chart

Manual control mode, the operator can through the button or touch screen to adjust the following modules and control, including ozone generator, the desulfurization denitration one tower, desulfurization tower and alkali lye configuration. The manual control flow chart of desulfurization is shown as follows Figure 2.

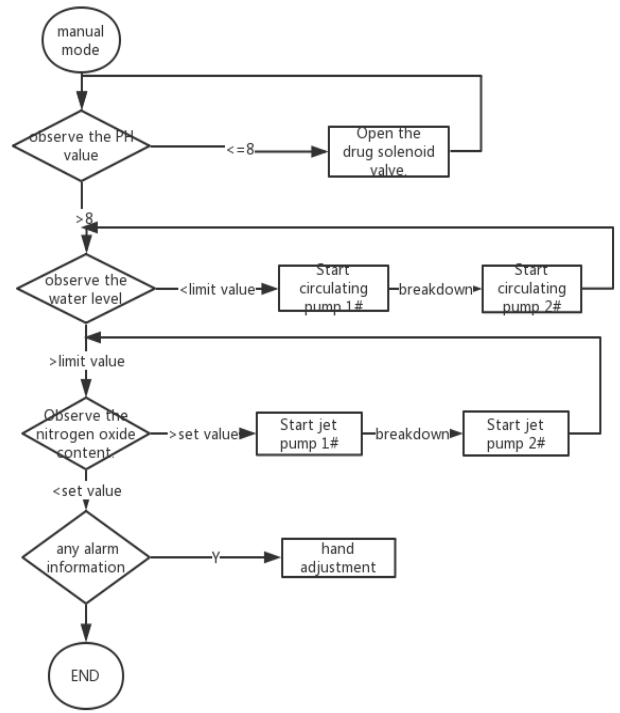

Figure 2. the manual control flow chart of desulfurization

In the desulfurization and denitrification module, the touch screen on the operating cabinet can observe the nitrogen oxide content in the flue gas emissions, the change of $\mathrm{PH}$ value in the tower and the liquid level of desulfurization When the desulfurization and selling tower is too low, the operator presses the liquid level control key on the touch screen, and the circulating pump 1 is started, and the circulating water is added to the tower. When the PH value of the tower is less than 8 , the operator presses the additive button on the touch screen, and the lye circulation pump is activated. The lye pump is used to transport lye to the denitration system. When the nitrogen oxide concentration in the flue gas exceeds the standard, jet pump 1 can be manually open, the lye is sprayed into the desulfurization and desulfurization tower. When the jet pump 1 fails, the backup jet pump 2 can be opened. If the injection pump 2 also fails, it will issue a fault message warning to the PLC.

In automatic control desulfurization and denitrification module flow chart as shown in Figure 3.

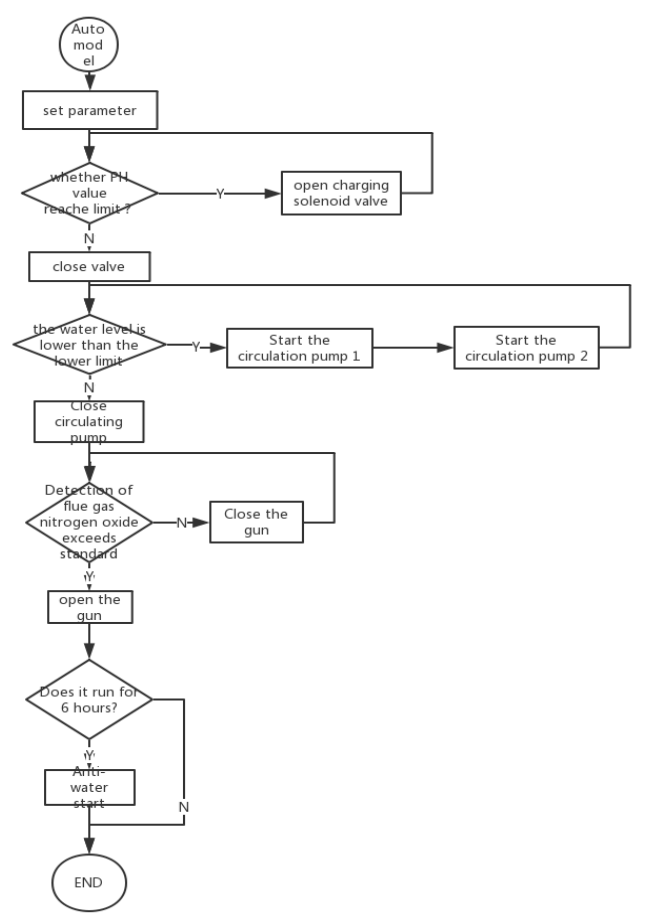

Figure 3. the automatic control flow chart of automatic control desulfurization and denitrification

After admin login, the indicators in a PC or a touch screen setting, such as setting the desulfurization tower of out of stock level, the tower PH concentration limit. After the information is set up, the PLC will immediately monitor whether the alkali solution is needed in the desulfurization and denitrification tower. When the nitrogen oxide content in the fume on-line monitor is too high, the control jet pump 1 is activated until it reaches a certain level. When the jet pump 1 fails, it will send a fault alarm to the PLC and automatically start the backup injection pump 2 to spray the urea solution into the reactor. When the nitrogen oxide in the flue gas is stabilized to a lower value, the system will automatically close the jet pump and wait for the next program loop.

\subsection{The software interface design}

Operator can be realized in the cab through the liquid crystal display the keyboard and mouse for boiler load ozone generator The granite import and export temperature and pressure desulfurization denitration towers import and export temperature and pressure of 
alkaline PH system control and monitoring of running status of equipment, according to the change of the operation parameters of the subsystems of the adjustment and operation Have advanced use safety and reliability Scalability, etc

PC monitor software adopts kingview6.5, this software provides a rich, simple easy to use interface, support a large number of graphical elements and gallery elf to visual construction interface, the product of the historical curve, report forms and web publishing function improved and improvement, functionality and usability of the software had the very big enhancement.

It with Siemens PLC to realize better communication, through the build process painting surface, set variables, control strategy, finally realizes the control function of painting into status, monitoring the main page, motor parameters setting, manual control, sensors, alarm, report management, data visualization operation such as user login interface.

In the PC interface design of flue gas desulfurization denitration system, mainly divides into: ozone desulfurization denitration main interface, ozone circulating pump control interface, the desulfurization tower of out of stock control interface, each including control interface, parameter setting, report interface, real-time curve, alarm, interface, etc.

The main interface design of ozone desulfurization and denitrification is shown in the Figure 4.

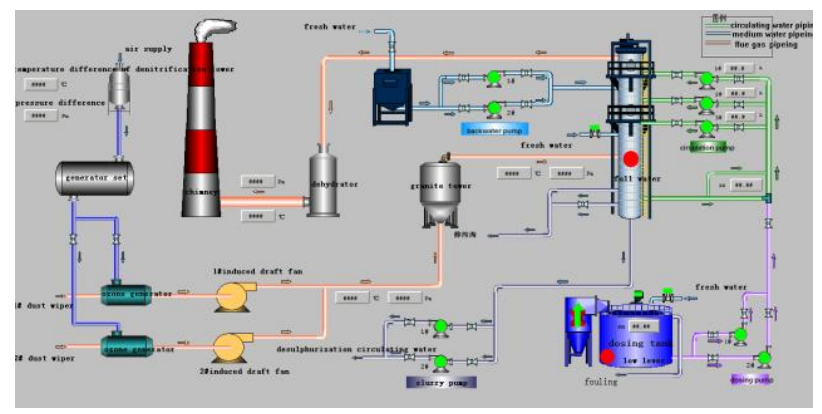

Figure 4 ozone desulfurization and denitrification interface

The interface shows the whole process of desulfurization and denitrification. The process includes smoke from the boiler outlet and is discharged through the chimney. The data and status of the above desulfurization and denitrification modules can be displayed in real time.

If a certain module's online remote monitoring and adjustment is required according to the operation of the flue gas, the corresponding position can be clicked to bring up the adjustment dialog box. The following Figure 5 shows the selection of control mode of circulating pump in the control tower of desulfurization and desulfurization.

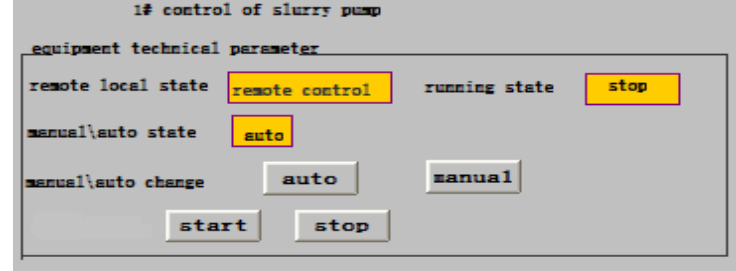

Figure 5 Mode selection dialog

The operator can also use the graph to conduct online observation and data comparison. As shown in the Figure 6 below for real-time pressure curve, the picture, a total of four groups of curve respectively shows: production load pressure, the granite column inlet pressure, the desulfurization denitration tower export pressure, gas flow rate.. At the top right of the screen, there are two modules: printing and history. The function of the printing module is to print the existing curve directly.

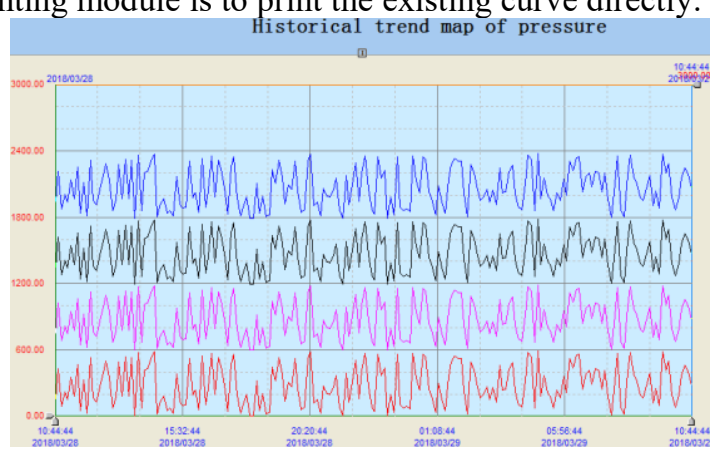

Figure 6 trend map

\section{Conclusion}

So far, desulfurization denitration in the design of this control system has been successfully into the actual production, obvious effect, achieve the expected goals, after the completion of the renovation project, $\mathrm{NOx}$, and dust, $\mathrm{SO}_{2}$ emissions were $35.3 \mathrm{t} / \mathrm{a}, 2.88 \mathrm{t} / \mathrm{a}, 17.12 \mathrm{t} / \mathrm{a}$. The current project adopts "electrostatic precipitation, dust removal efficiency $99.5 \%$;Magnesium oxide desulfurization and desulfurization efficiency $90 \%$; This project USES the oxidation denitrification process to purify the boiler flue gas, the denitrification efficiency is $85 \%$, the desulfurization efficiency is $25 \%$, the dust removal efficiency is $80 \%$, the environmental benefit and the social benefit are remarkable.

\section{Acknowledgements}

it is supported by Shandong higher science and technology project. ( A project of Shandong Province Higher Educational Science and Technology Programe. J16LN90)

\section{References}

1. LI Xiao-bin, Design of flue gas desulfurization control system based on PLC(2014). 
2. Ji zhengbiao,Design and Implementation of Efficienty gas desulfurization flue gas desulfurization control system based on PLC(2015).

3. LU Ping.Process design of ozone desulfurization and denitrification.(2017)

4. WANG Lili.Pneumatic Handling Robot Control System Based on PLC Design(2014)

5. FAN Zong-liang.Research Progress in Simultaneous Desulfurization and Denitrification Technologies for Flue Gas(2015) 